\title{
Using Infrared Technology to Locate and Monitor American Woodcock Nests
}

THOMAS J. KELLER, ${ }^{1}$ Pennsylvania Game Commission, 2001 Elmerton Avenue, Harrisburg, PA 17110

SAMARA TRUSSO, Pennsylvania Game Commission, 2001 Elmerton Avenue, Harrisburg, PA 17110

IAN D. GREGG, Pennsylvania Game Commission, 2001 Elmerton Avenue, Harrisburg, PA 17110

LISA WILLIAMS, Pennsylvania Game Commission, 2001 Elmerton Avenue, Harrisburg, PA 17110

\begin{abstract}
Methods for locating American woodcock (Scolopax minor; hereafter woodcock) whether individuals, nests, or broods, have remained largely unchanged for more than 75 years, but use of current technology has the potential to increase efficiency and decrease observer-caused disturbance. Primary methods of searching for and locating woodcock have included the use of pointing dogs, and telemetry after capture using mist nets, nightlighting, or live traps. We tested the feasibility of using Forward Looking Infrared Radar (FLIR) cameras to locate individual woodcock, nests, and broods in the spring (24 March - 11 May) of 2015 as part of a research project to determine the timing of nest initiation along 3 American Woodcock Singing-Ground Survey (SGS) routes in southwestern Pennsylvania. By using FLIR to search potential woodcock nesting cover adjacent to SGS routes, we located a total of 28 nests and 4 broods, 2 of which were not linked to a previously known nest. We also located 180 individual woodcock. Searching took place over a total of 22 days, not all contiguous, for a total of 58.05 hours. Nest-searching efficiency using FLIR was 0.48 nests/hour compared to published reports of efficiency using historical search methods ranging from $0.03^{-0.4}$ nests/hour. The FLIR method is not only more efficient, but provides a non-intrusive approach to locating and monitoring nesting woodcock. In addition to nesting ecology, FLIR may have additional applications in woodcock research, including improving efficiency of capture methods and monitoring nocturnal behavior and habitat use. The technology also proved to be excellent at locating other birds and mammals, and therefore has many possible uses in wildlife research.
\end{abstract}

Proceedings of the American Woodcock Symposium 11: 256-262

KEY WORDS: American woodcock, display, Forward Looking Infrared Radar (FLIR), nest, nest search, nest monitoring, Pennsylvania, Scolopax minor

Infrared technology was used as early as the 1960s in the field of wildlife management (Galligan et al. 2003), although until fairly recently the primary use has been to survey large mammals from aircraft. Within the past decade or so, several studies have been conducted on the efficacy of using Forward Looking Infrared Radar (FLIR) to locate smaller-sized birds for capture (Mills et al. 2011, Chavarria et al. 2012), to monitor activity from a distance (Long and Locher 2011), or to search for nests (Galligan et al. 2003). Several important factors that can limit FLIR efficacy have been identified. Solar heating of inanimate objects on the ground (rocks, coarse woody debris, etc.) can create a thermal washout and diminish the contrast needed between a bird's body-heat signature and the cooler background (Boonstra et al. 1995, Garner et al. 1995, Galligan et al. 2003, Chavarria et al. 2012). Density of surrounding cover can block the view of the camera and mask the heat signature (Galligan et al. 2003, Long and Locher 2011, Chavarria et al. 2012). Topography was also found to be a limiting factor (Long and Locher 2011). Finally, the

1 email: thomasjkeller@hotmail.com

https://doi.org/10.24926/AWS.0133 CC BY 4.0 
cost of FLIR units, although decreasing, is still high in comparison to other methods of locating birds.

There are many positive aspects of using FLIR, however. Not only can birds as small as passerines be located, but incubated eggs can also be located with the camera due to their heat signature (Galligan et al. 2003). When paired with other methods such as nightlighting or use of dogs in locating birds, FLIR increases location and/or capture rates (Galligan et al. 2003, Chavarria et al. 2012, Mills et al. 2011). In the case of clapper rail (Rallus crepitans) capture, Mills et al. (2011) found the use of FLIR, nightlighting, and airboat together produced a capture rate of 6.9 rails/ $\mathrm{hr}$, whereas trapping alone resulted in $0.019 \mathrm{rails} / \mathrm{hr}$, and nightlighting using an aluminum boat produced o.o rails/ hr. Probably the greatest positive application of FLIR is the non-intrusive ability to monitor birds and their nests (Galligan et al. 2003, Long and Locher 2011, Chavarria et al. 2012), which can prevent direct injury or mortality to birds (Ammann 1973, Chavarria et al. 2012) and decrease abandonment or predation on nesting birds and eggs or broods due to investigator disturbance (Gotmark 1992, Murphy and Thompson 1993). A study in Maine found that $28 \%$ of woodcock nests were negatively impacted by the researchers during the course of a study that did not use FLIR (McAuley et al. 1996).

We used FLIR as part of a larger pilot study to determine seasonal timing of peak display and peak nest initiation by woodcock within southwestern Pennsylvania (Keller 2016). We hypothesized that FLIR could be an especially efficient way to locate and monitor woodcock nests during both the egg-laying and incubation periods while also minimizing disturbance to nesting females.



Figure 1. Map of southwestern Pennsylvania showing American woodcock singing-ground survey routes on which we evaluated FLIR efficiency for locating woodcock and their nests, with insert map of the state of Pennsylvania.

\section{Study Area}

As part of the study of Keller (2016) we conducted singing-ground surveys (SGSs) at 3 routes selected within southwestern Pennsylvania during the period 24 March 11 May 2015. These 3 survey routes represented 3 primary vegetation communities within southwestern Pennsylvania (Fig. 1). These included: 1) extensive, open grassland singing grounds surrounded by contiguous mature and early-successional forests (Route 108), 2) a conglomerate of agricultural and warm-season grass fields as singing grounds with a surrounding patchwork of fencerows and both early-successional and mature woodlots (Route 427 ), and 3) roads where trees were cut within 7.62 meters along either side to promote early-succession, bordered by adjacent small herbaceous openings ( $<4.04$ hectares) and surrounded by contiguous forest in various stages of succession (Route 52). We characterized cover types within 0.32 kilometers (i.e. the approximate distance an observer can detect a singing male [Bergh, 2011]) of each survey route as mature forest, early-successional forest or shrub, and grassland. We surveyed each route during $>14$ evenings during the survey period.

\section{Methods}

\section{NEST SEARCHING}

After completion of an evening survey route, we returned to $\geq 1$ singing ground along the route and systematically searched for nests in nesting habitat and locations where singing males were heard during the survey. We identified nesting habitat by evaluating known nesting habitat preferences using ArcMap GIS software and a variety of layers including aerial imagery, surface water, topographic, and existing forestry stands on game lands when available. Historic nesting habitat preferences within Pennsylvania were determined to be young, early-succession hardwood stands with high stem density and minimal invasive vegetation (Liscinsky 1972, Dessecker and McAuley 2001, Palmer 2008, Miller 2010). By identifying singing grounds during an SGS survey, marking singing males on a route map, and listening to singing males during moonlit nights, we attempted to search those areas with a high likelihood of supporting nests. We initiated searches within 2 hours post sunset, and search efforts lasted anywhere from 15 minutes to $>5$ hours. Individual observers conducted searches, except during 5.4 hours when an additional observer was being trained. Trainee hours were not counted towards the total search time used to estimate searching efficiency (i.e., number of woodcock nests located per hour; see below). Observers used FLIR cameras and moved slowly through possible nesting habitat. We searched areas opportunistically; and used neither grids nor transects. We searched for nests when conditions were optimal for avoiding background solar heating: cool, overcast, or wet weather and nighttime to early-morning 
periods. We documented all discovered nests and broods including location coordinates, number of eggs, number of young, and other pertinent information. If incubation stage could not be readily determined through egg observation we continued to periodically monitor a subset of the nests non-intrusively using FLIR until eggs hatched.

\section{EQUIPMENT}

We used 2 different FLIR during nest searching: Recon M24 640x480 (hereafter Camera 1) and Sierra Pacific Innovations, IR 250D (hereafter Camera 2; the Pennsylvania Game Commission does not endorse these manufacturers). Camera 1 weighed $0.39 \mathrm{~kg}$ with batteries installed. This camera had 2 digital zoom levels ( $2 \mathrm{x}$ and $4 \mathrm{x}$ ) beyond the normal, wide field of view, had adjustable focus and a self-adjusting brightness display, and had an overall size of $11.7 \mathrm{~cm} \times 7.6 \mathrm{~cm} \times 6.4 \mathrm{~cm}$. This camera showed the gradient of heat in black and white, and had the ability to switch from heat showing in white or black. Camera 2 weighed $1.81 \mathrm{~kg}$ with batteries installed, had 1 digital zoom level (2x) and an adjustable focus, and its overall size was $25.4 \mathrm{~cm} \mathrm{x}$ $10.2 \mathrm{~cm} \mathrm{x} 14 \mathrm{~cm}$. Camera 2 also had the ability to switch from heat showing in black or white. Both cameras had the ability to attach a recording device. We used each camera in various temperatures ranging from -1.7 to $25.6^{\circ}$. We also used both cameras in light to heavy fog, and light to heavy rain. We used Camera 1 during heavy snowfall.

\section{NEST SEARCHING EFFICIENCY RATE}

We calculated search efficiency as the number of woodcock nests located per hour. We recorded the number of minutes spent nest searching at each location per night and the numbers of nests located. We then summed all minutes, converted to hours, and divided the total number of nests by the total number of hours spent searching. Although our primary focus was on locating nests, we also calculated search efficiency for all woodcock (total number of woodcock located divided by total number of hours spent searching) and investigated use of the FLIR for woodcock capture and other behavioral observations.

\section{Results}

We used FLIR to search a total of 58.05 hours ( 3,483 minutes) over 22 days. We tallied days based on the day that the FLIR survey began, as many were overnight and extended into the following calendar day. Search days were not always consecutive. Most surveys were started within 1 hour of sunset, but this was not always the case depending on weather or travel conditions. We located 180 woodcock; 28 of these were nesting females and 4 were brooding females, 2 of which were associated with a previously located nest as they were found within meters of the nest soon after hatch. Search efficiency rate was 0.48 nests/ hour and 3.1 birds/hour. Efficiency varied among routes and search areas. The route 108 search area had the highest nest search efficiency rate with 0.57 nests/hour and 3.44 birds/hour. Route 427 search area had an efficiency rate of 0.55 nests/hour and 3.09 birds/hour. Route 51 search area had the lowest efficiency rate of 0.10 nests/ hour and 2.83 birds/hour.

With 4 exceptions that were approached only once to determine how closely we could approach nests without causing the female to leave, we approached nests no closer than $1 \mathrm{~m}$ when searching or during subsequent monitoring. We often monitored nests from up to $6 \mathrm{~m}$ away depending on vegetation density.

\section{EQUIPMENT COMPARISON}

Initially, we used both cameras to search for woodcock and nests, and we tested cameras against each other for several characteristics. After the initial 2 surveys on route 427 , we predominantly used Camera 1 for searching and used Camera 2 only for recording to document efficacy of FLIR in locating and monitoring woodcock. We found Camera 1 was more efficient at locating and quickly monitoring for presence or absence of incubating female woodcock. Camera 2 provided both a more detailed image of woodcock once located and video recording capabilities for documentation. The weight, eye relief, and narrow field of view limited the utility of Camera 2. Camera 2 did, however, have the ability to focus very clear images of heat signatures (Fig. 2) and provided images that enhanced our ability to identify species. Camera 1 did not provide as clear an image (Fig. 3), but with its wide field of view, compact size, and lightweight mobility, we found it to be more useful for locating woodcock heat signatures.

During the course of the project, we identified 10 different bird species, 11 species of mammals, 1 reptile, 1 insect, and 1 plant species (Table 1 ) with the use of FLIR.

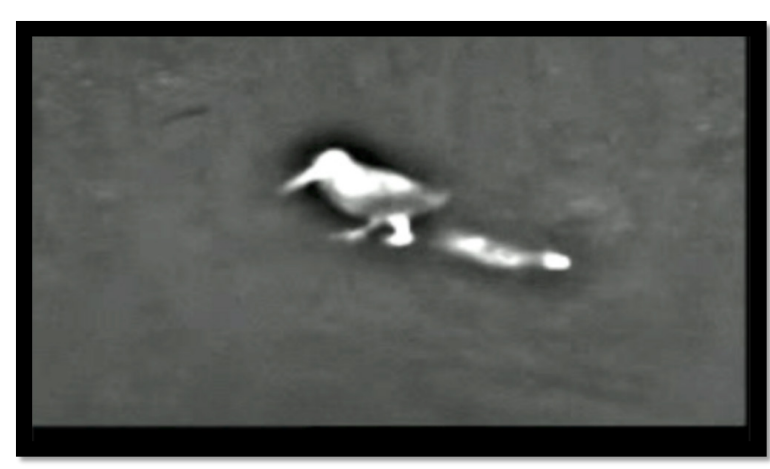

Figure 2. Still frame of an American woodcock using the Sierra Pacific Communications IR 250D FLIR camera. This woodcock had just stood up from its nocturnal roost within an open forb stand and began walking forward. 


\section{Discussion}

\section{SEARCH METHODOLOGY}

When using FLIR to search for woodcock, we found it was easiest to wear a headlamp, and while looking through the camera with 1 eye searching for heat signatures, to keep the other eye open for navigating through vegetation. This took practice, but in time a searcher was easily able to train each eye to focus on separate tasks. We also carried a rechargeable spotlight that could be used to assist in identifying animals we located via their heat signatures.

\section{LIMITATIONS}

We confirmed that FLIR does not detect heat signatures of woodcock through solid vegetation (e.g., tree trunks, leaves) as found in previous research (Galligan et al. 2003, Long and Locher 2011, Chavarria et al. 2012); we did discover, however, that it works well through grasses, early-successional forest woody vegetation, etc. We also found that conifer trees radiate more heat than any other tree species, and conifer species with high needle density can impede detection of heat signatures associated with woodcock and other animals.

We also observed that thick fog impedes detection of heat signatures using FLIR. Rain, unless very heavy, did not negatively affect detection of woodcock using FLIR. In fact, searching using FLIR after or during rain was often very productive as vegetation, coarse woody debris, rocks, and other objects cool rapidly during rain. We also confirmed that as ambient temperature rises, detecting woodcock or other animals using FLIR can become more difficult because of additional heat signatures on the land-

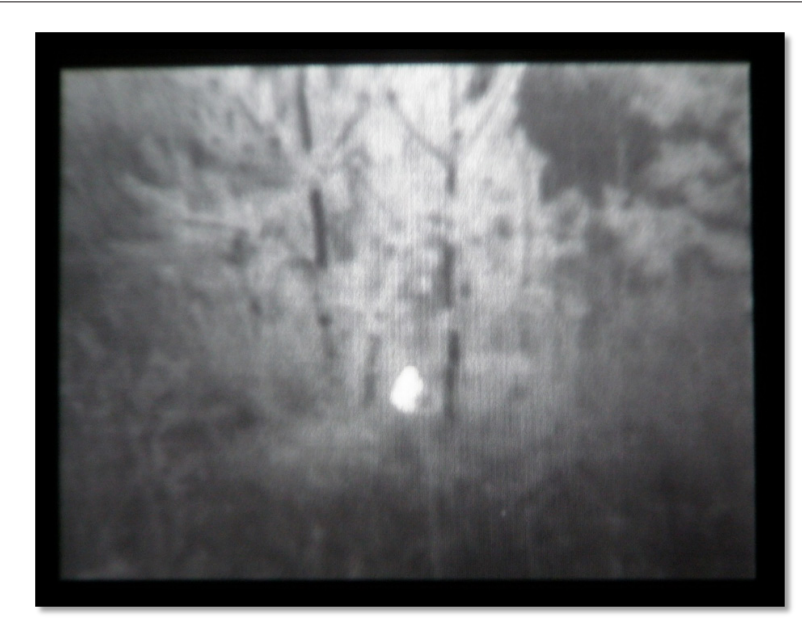

Figure 3. Photograph of nesting American woodcock through the eye piece of the FLIR Recon M24 camera. Note both the white image of the bird and the brightness (heat signature) of the small conifer tree under which the woodcock placed her nest. scape (Boonstra et al. 1995, Garner et al. 1995, Galligan et al. 2003, Chavarria et al. 2012). When searching for woodcock during the beginning of the project (24 March), there were patches of snow still covering the ground and temperatures below freezing at night. Due to the temperature differential, woodcock and other animal heat signatures contrasted well with the cool background. During the latter part of the project (second week of May), daytime temperatures in excess of $30^{\circ}$ warmed inanimate objects and also bare ground, which can often be found in habitat

Table 1. Species located and identified using FLIR during research on American woodcock nest initiation in southwestern Pennsylvania, 24 March through 11 May 2015.

\begin{tabular}{ll}
\hline Common Name & Scientific Name \\
\hline Birds & Turdus migratorius \\
American robin & Scolopax minor \\
American woodcock & Agelaius phoeniceus \\
Red-winged blackbird & Pipilo \\
Eastern towhee & erythrophthalmus \\
& Dumetella carolinensis \\
Gray catbird & Meleagris gallopavo \\
Wild turkey & Bonasa umbellus \\
Ruffed grouse & Cardinalis cardinalis \\
Northern cardinal & Spizella pusilla \\
Field sparrow & Melospiza melodia \\
Song sparrow &
\end{tabular}

\section{Mammals}

White-tailed deer

Flying squirrel

North American porcupine

Striped skunk

Virginia opossum

Eastern cottontail

Woodland jumping mouse

Meadow jumping mouse

Meadow vole

Odocoileus virginianus

Glaucomys spp.

Erethizon dorsatum

Mephitis mephitis

Didelphis virginiana

Sylvilagus floridanus

Napaeozapus insignis

Zapus hudsonius

Microtus

pennsylvanicus

White-footed mouse

Peromyscus leucopus

Deer mouse

Peromyscus

maniculatus

\section{Reptiles}

Eastern box turtle

Terrapene

carolina carolina

\section{Plants}

Eastern skunk cabbage

Symplocarpus foetidus

\section{Insects}

June bug

Phyllophaga spp. 
preferred by woodcock. When this occurred, search times increased and the shape and size of heat signatures became increasingly important to positively identify a woodcock or other animal.

The most significant limitation in our study was observer familiarity with the equipment and search image. When the observer understood the nuances of the camera, how auto adjustments operate, and particularly what a nesting woodcock heat signature looks like in comparison to a non-nesting woodcock, rock, similar-sized bird (e.g., ruffed grouse [Bonasa umbellus]), or rabbit (Sylvilagus spp.), successful use of the equipment increased dramatically.

\section{CONFIRMING NESTING}

When we located a woodcock with FLIR, we used a spotlight to confirm species identification. We developed the ability to identify woodcock via their heat signatures through experience, but there were several cues that helped identify a nesting woodcock using FLIR. Nesting female woodcock would not move unless approached within centimeters, and sometimes not until touched. Nesting woodcock would not move any part of their body, including their head, as we approached nests. They held perfectly still, so watching the head closely when approaching provided important cues as to whether the bird was on a nest. When we approached a woodcock not on a nest within a meter it would generally move its head or shift position, sometimes standing, walking away, or flushing. Similar movement occurred both by woodcock we detected using FLIR and via nightlighting.

Nesting female woodcock also exhibited what we describe as a "melted" appearance in the FLIR. They appeared as if their bottom half had melted into the ground because of their shallow nest structure and flattened body covering the eggs or a brood. Male woodcock or females not nesting would often appear more rounded underneath, even when sitting on the ground.

Using a spotlight in conjunction with the FLIR provided confirmation that what the observer was seeing was indeed a woodcock. It also helped illuminate the surrounding habitat and provided a clear view of any behavior that helped determine whether the woodcock was nesting.

\section{ADVANTAGES}

Compared to traditional methods of locating woodcock, and specifically nesting females, FLIR showed several definitive advantages. The primary traditional method for locating woodcock has been with pointing dogs. Several studies (Gregg and Hale 1977, Gregg 1984, Coon et al. 1982, Causey et al. 1987, Miller 2010) in which dogs were used to locate woodcock or nesting females reported varied success rates (Table 2). Using FLIR was more effective than the use of pointing dogs at locating nests and caused less nest disturbance than either pointing dogs or the combination of mist-netting and radio-telemetry (Ammann 1973, McAuley et al. 1996, Daly et al. 2013). We acknowledge

Table 2. Comparison of reported efficiency of various search methods in locating American woodcock nests.

\begin{tabular}{|c|c|c|c|c|c|c|c|c|}
\hline Author & $\begin{array}{c}\text { Year } \\
\text { Published }\end{array}$ & Location & Man hr & Dog hr & Years & $\begin{array}{c}\text { Nest/ } \\
\mathbf{y r}^{\mathbf{a}}\end{array}$ & Nests/hr & Search method \\
\hline Simon et al. & 1971 & $\mathrm{PA}$ & & 538 & 2 & 7.5 & $0.03^{b}$ & Pointing Dog \\
\hline Wenstram & 1974 & $\mathrm{MN}$ & & & 2 & 2.5 & & Multiple \\
\hline Bourgeois & 1977 & MI & 92 & & 1 & 16 & 0.17 & Pointing Dog \\
\hline Gregg and Hale & 1977 & WI & & & 2 & 13.5 & & Pointing Dog \\
\hline Coon et al. & 1982 & $\mathrm{PA}$ & 84 & 312 & 3 & 11.4 & $0.4(0.11 b)$ & Pointing Dog \\
\hline Gregg & 1984 & WI & 483 & & 4 & 14.7 & 0.12 & Pointing Dog \\
\hline Causey et al. & 1987 & $\mathrm{AL}$ & & 1714.5 & 9 & 5 & $0.06^{\mathrm{b}}$ & Pointing Dog \\
\hline $\begin{array}{l}\text { Murphy and } \\
\text { Thompson }\end{array}$ & 1993 & $\mathrm{MO}$ & & & 3 & 10 & & Pointing Dog \\
\hline McAuley et al. & 1996 & $\mathrm{ME}$ & & & 3 & 29.7 & & Radiotelemetry \\
\hline Miller & 2010 & $\mathrm{PA}$ & 103 & & 2 & 4 & 0.08 & Pointing Dog \\
\hline Daly et a. & 2013 & $\mathrm{MN}$ & & & 2 & 26 & & Radiotelemetry \\
\hline Keller & $2015^{c}$ & $\mathrm{PA}$ & 58.05 & & 1 & 28 & 0.48 & FLIR \\
\hline \multicolumn{9}{|c|}{$\begin{array}{l}\text { a Nest/Year may not be comparable between study areas if a measure of effort was not provided. } \\
\text { b Based on dog hours. }\end{array}$} \\
\hline
\end{tabular}


that variations in woodcock population density could also affect differences in search efficiency between our research and other published research; however, although we lack density data to evaluate this possibility, our counts of singing males per stop on survey routes were similar to several of those reported from high-quality woodcock habitat in other studies (Miller 2010, Daly et al. 2013). We conclude, therefore, that using FLIR to locate woodcock nests is the primary factor accounting for the much higher search efficiency in our study.

Several studies have implicated observer disturbance as a contributing factor to nest failure during research or monitoring (Mendall and Aldous 1943, Ammann 1973, McAuley et al. 1996, Chavarria et al. 2012). Several potential reasons have been suggested for this decreased nest success, including humans and search dogs leaving a scent trail directly to the nest, woodcock being disturbed and abandoning nests, or eggs and chicks being stepped on by either a dog or a human (Ammann 1973). Using FLIR, we were able to locate, identify, and then monitor nests, all from a distance of 1-6 $\mathrm{m}$ depending upon vegetation structure in the vicinity of the nest. At no point during our study did we incidentally flush or injure an incubating female or disturb a nest, as has been recorded using other methods in previous research (Mendall and Aldous 1943, Ammann 1973, McAuley et al. 1996, Chavarria et al. 2012). We cannot definitively exclude the possibility that observer presence and/or the presence of human scent did not contribute to nest failure in the nests we located using FLIR. However, our methods minimized researcher-caused predation risk to nesting females by keeping human scent away from the immediate vicinity of the nest, and we did not disturb vegetation immediately surrounding the nest. There was no direct evidence of predation or nest failure that we attributed to the use of FLIR or human disturbance during searching or subsequent monitoring as was found with historical methods (Ammann 1973, Chavarria et al. 2012), nor did we note abandonment (Gotmark 1992, Murphy and Thompson 1993). In summary, we achieved our objective of evaluating using FLIR as an effective and efficient way to locate and monitor woodcock nests.

\section{OTHER POTENTIAL USES OF FLIR IN WOODCOCK RESEARCH Woodcock capture}

Spotlighting or nightlighting is a proven method for approaching and capturing woodcock (Sheldon 1967, Shuler et al. 1986). We tested the FLIR 1 night to locate woodcock for capture. Capture occurred on a rainy, moonless night; weather classified by Sheldon (1967) as being the optimal conditions to capture woodcock while nightlighting. We successfully approached 4 woodcock in open habitat to within $6 \mathrm{~cm}$, and captured 1 easily with a net. This experience demonstrated that FLIR has the capability to be a useful tool for initially locating birds during nightlighting projects, and for relocating woodcock following a failed capture attempt.

\section{Nocturnal habitat use}

We found that, within old-field cover where mowing occurs only along borders or in single mower-width paths through the interior of fields, displaying males consistently selected these mowed areas versus non-mowed areas. When mown paths were curved and male woodcock could not see each other on the ground, males often would display in very close proximity to one another. Woodcock commonly used these mown areas for nocturnal roosting and could be found within these mowed paths in a variety of weather conditions. These observations may provide further evidence consistent with the predation risk hypothesis described by Masse (2014), which surmises that woodcock prefer nocturnal roosting in openings to avoid predation. Using FLIR provided an enhanced ability to observe behavior and habitat use of male woodcock, much of which is not well described.

\section{Nocturnal behavior}

Although not the primary purpose of our study, FLIR provided a means to observe woodcock nocturnal behavior. FLIR allowed observers to monitor woodcock with apparently little or no influence on their behavior after sunset and provided the opportunity to view both flight and woodcock behavior while they were on the ground. Using FLIR, we were able to observe male woodcock from close proximity during their courtship behavior both while they were on the ground and airborne. Having the ability to observe woodcock at night may facilitate better understanding of woodcock behavior during this period and of their interactions with each other and their environment in activities such as feeding, roosting, or predator avoidance.

\section{Acknowledgments}

Our sincere thanks to T. Colt and D. Bakner for data collection. Thanks to J. Johnson for statistical analysis, J.P. Seman and C. Wellman for equipment lending, and Dr. M. Brooks, B. McCombie, J. Farabaugh, and P. Anderson for support throughout the project. Special thanks to T. Cooper, D. Krementz, D. Anderson, S. Oldenburger, K. Koch, and one anonymous reviewer who greatly enhanced the quality of this manuscript.

\section{Literature Cited}

Ammann, G.A. 1973. Methods of capturing American woodcock broods. International Congress of Game Biologists Proceedings 11:33-39.

Bergh, S.M. 2011. Factors influencing detection of American woodcock during singing-ground surveys. Thesis. University of Minnesota, Minneapolis, Minnesota, USA. 
Boonstra, R., J.M. Eadie, C.J. Krebs, and S. Boutin. 1995. Limitations of far infrared thermal imaging in locating birds. Journal of Field Ornithology 66:192-198.

Bourgeois, A. 1977. Quantitative analysis of American woodcock nest and brood habitat. Pages 109-118 in Proceeding of the Sixth Woodcock Symposium, US Fish and Wildlife Service, Washington, D.C., USA.

Causey, M.K., M.K. Hudson, and T.P. Mack. 1987. Breeding activity of American woodcock in Alabama as related to temperature. Pages 373-377 in Proceedings of the annual conference Southeastern Association of Fish and Wildlife Agencies, 4-7 October 1987, Mobile, Alabama, USA.

Chavarria, P.M., A.R. Kocek, N.J. Silvy, and R.R. Lopez. 2012. Use of portable infrared cameras to facilitate detection and capture success of Montezuma quail. Pages 333-338 in Proceedings of the Seventh National Quail Symposium, The University of Tennessee, National Bobwhite Conservation Initiative, Knoxville, Tennessee, USA.

Coon, D.R., B.K. Williams, J.S. Lindzey, and J.L. George. 1982. Examination of woodcock nest sites in central Pennsylvania. Pages 55-62 in T. Dwyer and G.L. Storm, Eds. Woodcock ecology and management. U.S. Fish and Wildlife Service, Wildlife Research Report 14, Washington, D.C., USA.

Daly, K.O., D.E. Anderson, and W.L. Brininger Jr. 2013. Assessment of techniques for evaluating American woodcock population response to best management practices applied to the demonstration-area scale. Minnesota Cooperative Fish and Wildlife Research Unit. Research work order No. 91, St. Paul, Minnesota, USA.

Dessecker, D.R., and D.G. McAuley. 2001. Importance of early successional habitat to ruffed grouse and American woodcock. Wildlife Society Bulletin 29:456-465.

Galligan, E.W., G.S. Bakken, and S.L. Lima. 2003. Using a thermographic imager to find nests of grassland birds. Wildlife Society Bulletin 31:865-869.

Garner, D.L., H.B. Underwood, and W. F Porter. 1995. Use of modern infrared thermography for wildlife population surveys. Journal of Environmental Management 19:233-238.

Gotmark, F. 1992. The effects of investigator disturbance on nesting birds. Current Ornithology 9:63-104.

Gregg, L.E., and J.B. Hale. 1977. Woodcock nesting habitat in northern Wisconsin. The Auk 94:489-493.

Gregg, L.E. 1984. Population ecology of woodcock in Wisconsin. Technical Bulletin No. 144. Department of Natural Resources. Madison, Wisconsin, USA.
Keller, T.K. 2016. Investigating the Timing of Peak Display and Nest Initiation of American Woodcock in Southwestern Pennsylvania. Thesis. Green Mountain College, Poultney, Vermont, USA.

Liscinsky, S.A. 1972. The Pennsylvania woodcock management study. Pennsylvania Game Commission Research Bulletin 171. Harrisburg, Pennsylvania, USA.

Long, A., and A. Locher. 2011. The efficacy of thermal imaging technology for documenting American woodcock on pine stands. Journal of the Arkansas Academy of Science 65:173.

Masse, R.J. 2014. American woodcock ecology and bird conservation in relation to forest management. Dissertation. University of Rhode Island, Kingston, Rhode Island, USA.

McAuley, D.G., J.R. Longcore, G.F. Sepik, and G.W. Pendleton. 1996. Habitat characteristics of American woodcock nest sites on a managed area in Maine. The Journal of Wildlife Management $60: 138-148$.

Mendall, H.L., and C.M. Aldous. 1943. The ecology and management of American woodcock. Maine Cooperative Wildlife Research Unit, University of Maine, Orono, Maine, USA.

Miller, H.E. 2010. The relationship between invasive shrubs and American woodcock (Scolopax minor) nesting success and habitat selection. Thesis. Green Mountain College, Poultney, Vermont, USA.

Mills, W.E., D.E. Harrigal, S.F. Owen, W.F. Dukes, D.A. Barrineau, and E.P. Wiggers. 2011. Capturing clapper rails using thermal imaging technology. The Journal of Wildlife Management 75:1218-1221.

Murphy, D.W., and F.R. Thompson III. 1993. Breeding chronology and habitat of the American woodcock in Missouri. Pages 12-18 in Proceedings of the Eighth Woodcock Symposium, US Fish and Wildlife Service, Washington, D.C., USA.

Palmer, W. 2008. Management plan for American woodcock in Pennsylvania 2008-2017. Pennsylvania Game Commission. Harrisburg, Pennsylvania, USA.

Sheldon, W.G. 1967. The book of the American woodcock. University of Massachusetts Press, Amherst, Massachusetts, USA.

Shuler, J.F., D.E. Samuel, B.P. Shissler, and M.R. Ellingwood. 1986. A modified nightlighting technique for male American woodcock. The Journal of Wildlife Management 50:384-387.

Simon, K.R., R.A. Coon, and J.S. Lindzey. 1971. Current status of woodcock research in Pennsylvania. Pages 206-216 in Proceedings of the Fourth Woodcock Symposium, US Fish and Wildlife Service, Washington, D.C., USA.

Wenstram, W.P. 1974. Habitat selection of brood rearing American woodcock. Pages 154-177 in Proceedings of the Fifth Woodcock Symposium, US Fish and Wildlife Service, Washington, D.C., USA. 